\title{
Formação de conselheiros escolares: uma política de resistência
}

Maria de Fatima Magalhães de Lima

Doutora em Educação pela Pontifícia Universidade Católica do Rio de Janeiro e professora substituta da Faculdade de Educação da UFRJ. Alba Valéria Baensi

Doutoranda em Educação pela Universidade Federal Fluminense

Resumo

Este artigo analisa uma política de formação continuada, implantada no estado do Rio de Janeiro, à luz do Programa Nacional de Fortalecimento dos Conselhos Escolares, num contexto de descontinuidade e extinção do Programa, em virtude da mudança do governo e da agenda política. Na análise foram utilizados dados dos perfis dos participantes e documentos oficiais, buscando integrar a literatura sobre o ciclo de políticas aos aspectos do federalismo brasileiro e ao contexto político atual. Os resultados apontam que esta formação se constituiu como uma política de resistência com considerável capilaridade territorial, sugerindo novas investigações e proposições sobre o apoio aos conselhos escolares.

Palavras-chave: Conselhos Escolares; Formação Continuada; Gestão Democrática.

\section{Abstract \\ Education course of school counselors: a policy of resistance}

This article analyzes a policy of continuing education implemented in the state of Rio de Janeiro, in the light of the National Program to Strengthening of the School Councils, in a context of discontinuity and extinction of the Program, due to the change of government and the political agenda. The analysis used data from the profiles of the participants and official documents seeking to integrate the literature on the cycle of policies to the aspects of Brazilian federalism and the current political context. The results show that this formation was constituted as a resistance policy with considerable territorial capillarity, suggesting new investigations and propositions on the support to the school councils.

Keywords: School Councils; Continuing Education; Democratic Management.

\section{Resumen}

\section{Formación de consejeros escolares: una política de resistencia}

Este artículo analiza la política de la formación continua, implantada en el estado de Rio de Janeiro, a la luz del Programa Nacional de Fortalecimiento de los Consejos Escolares, el contexto de la interruptión y la extinción del Programa, en virtud del cambio de lo gobierno y de la agenda politica. En las análisis fueran utilizados datos de los perfis de los participantes y de la legislación buscando integrar el ciclo de la políticas y los aspectos del federalismo brasileño y el contexto político. Los resultados indican que la formación de constitui em una de resistencia con la capacidad de capilaridad territorial, indicando nuevas investigaciones y propuestas sobre el tema y los consejos escolares.

Palabras claves: Consejos Escolares; Formación Continuada; Gestión Democrática. 


\section{Introdução}

Este trabalho tem como objetivo analisar uma política de formação continuada para conselheiros escolares, no âmbito do estado do Rio de Janeiro, que se constituiu a partir do desenho do Programa Nacional de Fortalecimento dos Conselhos Escolares (PNFCE), dirigida originalmente aos técnicos das secretarias municipais de educação.

O PNFCE e a formação continuada em âmbito local foram analisados à luz de referenciais teóricos do campo das políticas públicas, buscando integrar a literatura sobre o ciclo de políticas aos aspectos do federalismo brasileiro e ao contexto político atual.

Neste sentido, no desdobramento da análise foram apontados os desafios e as perspectivas deste curso semipresencial de formação continuada, que se caracterizou por ampliar o público-alvo estabelecido originalmente, num contexto de descontinuidade do PNFCE, como consequência da mudança da agenda política nacional após o processo de impeachment da Presidenta Dilma Rousseff em 20016. No encadeamento do impeachment, a eleição do Presidente da República em 2019 aprofundou as restrições de financiamento à educação e, consequentemente, a extinção de programas, projetos e ações educacionais implementados por governos anteriores. Neste sentido, o curso de formação continuada em tela se constituiu como um evento imprevisível, em vista do fechamento da "janela de oportunidades" (KINGDON, 2006), decorrente das mudanças dentro do governo.

$\mathrm{Na}$ análise da formulação e de aspectos da implementação do programa de formação no Rio de Janeiro, tomamos como base as fichas de inscrição para análise exploratória dos perfis dos participantes e da abrangência territorial, cotejados aos documentos oficiais.

Por fim, foram feitas considerações a partir dos desafios e perspectivas que permitem refletir como políticas públicas podem resistir e ser aprimoradas por gestores a partir de experiências locais, em diálogo com outras unidades federativas.

\section{Os conselhos escolares e a gestão democrática: caracterização, per- spectivas e desafios}

No Brasil, a gestão democrática está consolidada como princípio da educação pública na Constituição Federal de 1988 (Art. 206, VI) e nas leis infraconstitucionais (Lei de Diretrizes e Bases da Educação Nacional - LDB n 9.394/1996 e Lei n 13.005/2014), no sentido de estabelecer que os sistemas de ensino e escolas tenham 
como parâmetro para oferta, planejamento e organização do ensino, a construção da autonomia e da tomada de decisões com base em mecanismos de participação da comunidade escolar no âmbito da gestão.

A concretização da gestão democrática responde às reivindicações da transformação do Estado brasileiro no processo de redemocratização do país nos anos 1980, num contexto de acúmulo do debate político de diversas organizações e forças democráticas antagônicas à ditadura militar. Neste sentido, é tributária da recomposição do processo democrático no país, da retomada e ampliação dos direitos civis e políticos e de um crescente protagonismo de movimentos sociais, setores progressistas e da intelectualidade brasileira no debate público em torno da constituição de mecanismos de participação, controle e tomada de decisões nas esferas públicas da sociedade.

Essa perspectiva traduzia o desenvolvimento de uma nova cultura política, na qual os sujeitos, portadores de direitos, participam e interferem na “coisa pública”, no sentido de promover a cidadania e de garantir que os interesses populares e as demandas locais, legitimadas coletivamente, ganhassem visibilidade e fossem atendidas. A institucionalização de mecanismos participativos, compreendidos como instrumentos de alargamento do Estado e parte "de uma cultura de contra hegemonia à ordem dominante” (GOHN, 2003, p. 51), buscava subverter a lógica dos valores patrimonialistas e das relações clientelistas enraizadas no Estado brasileiro.

No campo educacional, de acordo com Mendonça (2000, p. 4), "naquele momento, a ideia de democratização da educação superava o conceito de escola para todos, incluindo a noção da escola como espaço de vivência democrática e de administração participativa”. Para o autor a defesa da descentralização tinha como fundamento suplantar o centralismo administrativo, que, embora tenha contribuído para a expansão da oferta educacional, tor nou as escolas distantes das comunidades em função do planejamento e da gestão serem realizados em níveis centrais, numa dinâmica hierarquizada da educação nacional.

Neste contexto de lutas pela ampliação dos espaços de participação política, os setores organizados da população brasileira, particularmente os educadores, ratificaram, na LDB, a gestão democrática como princípio basilar do ensino público do país, bem como instrumentos para operacionalizá-la e desenvolvê-la através de "agentes sociais e suas relações com o ambiente, como sujeitos da construção da história humana, gerando participação, corresponsabilidade e compromisso” (BORDIGNON; GRACINDO, 2001, p. 12). 
De acordo com a LDB, a gestão democrática, prerrogativa limitada à escola pública, regulada por sistema de ensino (Art. $3^{\circ}$, VIII), deve assegurar o princípio da participação dos profissionais da educação na elaboração do projeto pedagógico da escola (Art. 14, I) e da comunidade escolar e local, em conselhos escolares ou equivalentes (Art. $1^{\circ}$, II ). A LDB menciona, ainda, progressivos graus de autonomia; pedagógica, administrativa e de gestão financeira das unidades escolares da educação básica (Art. 15).

Contudo, o caráter procedimental que orienta a constituição e as dinâmicas que relacionam os agentes à gestão escolar, através dos conselhos ou colegiados escolares, não foi explicitado no texto da Lei, prevalecendo como pano de fundo da legislação o ordenamento federativo, que assegura a autonomia e a auto-organização dos entes federados na condução das políticas, sob um frágil regime de colaboração e assimetrias entre as esferas governamentais do país.

A este respeito, Abrucio (2010, p. 48) afirma que, “após a Constituição, o federalismo foi marcado por uma descentralização bastante pulverizada e com pouca coordenação entre os entes federativos”, contribuindo para a baixa efetividade de políticas, em vista de "uma ação estanque de cada esfera governamental, com poucos incentivos para a parceria e o entrelaçamento entre as unidades federativas” (ABRUCIO, 2010).

No caso brasileiro, além das tensões políticas, as desigualdades regionais agudizadas em algumas regiões, estados e municípios, se constituem como obstáculos técnicos e financeiros para ordenação territorial e organização sistêmica da educação. A ausência da regulamentação do pacto federativo que institucionalize a cooperação e o equilíbrio de responsabilidades entre as esferas de governo é um desafio que demanda de longa data medidas políticas de vulto nacional que induzam mudanças na estrutura de gestão e de planejamento da educação.

Como forma de vencer os resultados negativos do processo descentralizador fragmentado o Governo Federal buscou implementar nas últimas décadas, políticas, programas e ações de coordenação federativa, para induzir mecanismos de cooperação e coordenação entre os níveis de governo, como mecanismo de articulação federativa nacional. Neste sentido, o papel coordenador, indutor e financiador da União atua sincronicamente e em equilíbrio com a autonomia dos governos subnacionais na perspectiva da equidade.

No tocante aos conselhos escolares, instrumentos institucionalizados em âmbito nacional como estratégia para a gestão democrática, importa aqui destacarmos o papel dos estados, municípios e do Distrito Federal no estabelecimento de políticas, 
programas e ações específicas, particularmente as relacionadas à democratização da gestão do ensino público. Sobre esta questão a literatura tem reiterado que a implantação, a organização e o funcionamento desses organismos participativos na gestão ocorrem heterogeneamente, prevalecendo, em grande medida, o caráter protocolar, com a finalidade de cumprir a legislação, conforme evidenciado por Mendonça:

A maneira cartorial como são constituídos alguns colegiados tem levado ao seu funcionamento inadequado. Apesar do poder formal que possuem essas instâncias no encaminhamento de diferentes situações da convivência escolar, muitas vezes ele não é exercido por falta de consciência dos conselheiros em relação a esse poder (2001, p. 91).

Werle (2003) destaca, como um contraponto à distribuição equânime do poder, a assimetria das relações reforçadas nos conselhos escolares. Tais assimetrias estariam relacionadas ao nível de escolaridade, às diferenças de capital cultural, político e informacional entre os conselheiros e, neste aspecto, o presumível volume de recursos manejados pelos professores e pelos diretores, que detém maior domínio de conhecimento sobre o campo educacional e escolar. A primazia do exercício da palavra, por parte desses agentes estaria relacionada ao poder simbólico (BOURDIEU, 2010), que confere reconhecimento e legitimidade, possibilitando um lugar de destaque em relação aos demais integrantes do conselho, através de um consentimento tacitamente compartilhado.

De acordo com Paro (2007), outro problema, relacionado à concentração do poder, que parece influenciar na constituição dos conselhos como uma estrutura meramente formal, é o uso da autoridade do diretor para influenciar na escolha dos representantes da comunidade que atuarão como conselheiros. Este estratagema, operado por aqueles que, via de regra, ocupam a presidência dos conselhos, distorce a democracia representativa e contribui para que segmentos específicos, ou a comunidade escolar de modo geral, não reconheçam o conselho como espaço participativo, contribuindo para que o domínio do poder do diretor prevaleça na tomada de decisões.

Sobre o caráter dos conselhos escolares, Taborda (2009) relata que as transformações ocorridas no âmbito da gestão educacional, no contexto da Reforma do Estado dos anos 1990, contribuíram intensamente para desvirtuar o caráter democrático, a autonomia e a capacidade de auto-organização desses organismos. A constituição dos conselhos em Unidades Executoras ${ }^{1}$, como condição para gerir recursos financeiros

\footnotetext{
${ }^{1}$ No contex to da descentralização da gestão nos anos 1990, o Ministério da Educação (MEC) institui o Programa de Manutenção e Desenvolvimento do Ensino Fundamental (PMDE), modificado mais tarde para Programa Dinheiro Direto na Escola. O Programa consiste no repasse de recursos financeiros, em caráter suplementar, para o custeio e a manutenção das escolas.
} 
encaminhados à escola através de fontes governamentais, induziu a proliferação dos conselhos escolares e colegiados nas redes públicas de ensino. Mas, por outro lado, passou a atribuir-lhes propósitos empresariais e não necessariamente assegurou a participação dos diferentes agentes sociais da escola na gestão, a vitalidade desses organismos, ou o pleno exercício de suas competências e o seu funcionamento de fato.

Barroso (2013) e Lima (2001) discutiram o amplo conceito de participação, operado como elemento central nas medidas políticas e administrativas que foram tomadas no contexto das reformas dos anos 1990, cujos efeitos sobre a organização escolar e as estruturas de gestão são muitas vezes contraditórios e ambíguos. De acordo com os autores, tais medidas instituíram um novo ordenamento democrático, sob a regulação do Estado, numa perspectiva de desconcentração ou recentralização do poder. Deste ponto de vista, a participação da comunidade na gestão escolar está relacionada a um ordenamento da gestão com a finalidade de operacionalizar as políticas no âmbito local, numa evidente separação entre concepção (nível central) e execução (nível periférico). Este modelo de descentralização denominada por Lima (2001, p. 139) de "recentralização por controlo remoto" toma o local como imperativo para a consolidação da descentralização e da implementação das políticas pós-burocráticas, representando muito mais uma forma de participação imposta, com contornos normativos, "que deve ser claramente distinguida da participação na decisão, no governo, organização e administração da escola” (LIMA, 2001, p. 71).

Nessa linha, os conselhos escolares se constituíram numa das estratégias para a descentralização da gestão, que, embora não seja intrinsecamente democratizante, tem o potencial de convergir para a construção da autonomia e de espaços participativos pautados no diálogo, com a perspectiva de alterar as relações de poder estabelecidas na gestão escolar. Seria, portanto, possível, como afirmado por Barroso (2013), construir novas formas de regulação local de caráter "sociocomunitária”.

\section{Entre a proposição legal e ação local}

Se por um lado, a integração dos conselhos na gestão escolar se constituiu, de forma seminal, como potenciais mecanismos para a gestão democrática na perspectiva da autonomia local, por outro lado, o caráter compulsório de sua existência, para gerir os recursos financeiros da escola, pode ter contribuído, ambiguamente, para a proliferação desses organismos como “cartórios” escolares (NUNES, 1999), pautados pelas estratégias e discricionariedade dos diretores no âmbito da gestão escolar. 
Este distanciamento do virtuosismo político original e a heterogeneidade de interpretações e reinterpretações sobre o caráter e o papel destes organismos na gestão escolar parecem confirmar as lacunas entre a formulação e a implementação de políticas nas esferas do governo, reportadas nos estudos que representam uma nova geração de abordagem de análise de política, compreendendo-a como um ciclo contínuo, "cercado de armadilhas”, entrecortado por reformulações e mutações e por agentes que influenciam o processo de implementação (SABATIER, MAZMANIAN, 1993; HOWLETT, RAMESH, PERL, 2013). Distintamente das tradicionais abordagens top down, tais estudos enfatizam a importância de se compreender o papel dos agentes públicos na alteração dos rumos das políticas e a limitada capacidade dos governos em manter os termos normativos e controlar a discricionariedade e a influência dos agentes implementadores que operam na configuração do contexto da política (LOTTA, 2014).

Outro elemento que a literatura identifica como variável condicionante para o êxito de uma política pública é o desenho federativo de um país. Segundo Howlett, Ramesh e Perl (2013), o sistema federativo pode ser um empecilho para a implementação de políticas de caráter nacional. Os autores destacam que, nos sistemas unitários, a definição da hierarquia e a clara subordinação entre os níveis de governo favorecem a implementação de políticas centrais com demandas menos complexas de governança. Distintamente, nos sistemas políticos organizados como federação, como ocorre no Brasil, nos quais existem pelo menos dois níveis de governo, com margens de autonomia garantidas constitucionalmente e baixo ou nenhum grau de subordinação, é difícil desenvolver políticas públicas nacionais sem acordos intergovernamentais envolvendo negociações complexas e extensas, com desfechos imprevisíveis. Neste sentido, os autores alertam que em países organizados como federação é possível que diferentes governos locais tomem decisões que anulem ou enfraqueçam uma determinada política nacional. No caso brasileiro, tais decisões são ampliadas pela incorporação dos municípios como terceiro órgão da federação na Constituição Federal de 1988, com autonomia para gerir políticas com peso importante na vida dos cidadãos.

O PNFCE foi criado em 2004 e passou a integrar a agenda da política educacional a partir do primeiro mandato de governo do Presidente Luiz Inácio Lula da Silva (2003-2006). O Programa foi estruturado a partir do eixo da formação continuada, presencial e a distância, para técnicos das Secretarias Estaduais e Municipais de educação e também para conselheiros escolares, com o objetivo de fomentar a gestão democrática por meio do fortalecimento dos conselhos escolares numa perspectiva federativa e sistêmica. 
A adesão ao Programa está relacionada às necessidades dos sistemas de ensino, como informado no portal do Ministério da Educação (MEC). Deste modo, tem como proposição incrementar a constituição de conselhos escolares nas redes públicas de ensino, além de qualificar e intensificar a participação de professores, funcionários, pais, alunos, diretores e comunidade escolares nestes organismos, induzindo o alinhamento do funcionamento dos conselhos à prerrogativa de democratização da gestão educacional e escolar em âmbito nacional, conforme demanda o arcabouço legal.

\section{O Programa de Fortalecimento dos Conselhos Escolares na agenda da política educacional}

De acordo com Souza (2007, p. 69), “a formulação de políticas públicas constitui-se no estágio em que governos democráticos traduzem seus propósitos e plataformas eleitorais em programas e ações que produzirão resultados ou mudanças no mundo real". Nesse sentido, a eleição é uma oportunidade de expressar a vontade pública a respeito de um determinado projeto político, referendando seu aprofundamento, ampliação ou impondo a necessidade de sua mudança. Neste contexto, a disputa de ideias se traduz em plataformas eleitorais que expressam o confronto entre propostas de rupturas, de ajustes e de consolidação em relação a um projeto de governo que finaliza o exercício de seu mandato.

Kingdon (apud Capella, 2007, p. 100) sublinha, entretanto, que o momento eleitoral pode ser também um espaço de análise e crítica das ações deste mesmo governo, bem como das reações sobre a forma como suas políticas interferiram (favorável ou desfavoravelmente) na vida dos cidadãos, gerando inclusive a interrupção ou a descontinuidade de políticas.

Deste ponto de vista, o início de um novo governo se caracteriza como o momento mais próspero para mudanças na agenda política e proposição de novas ações. Possivelmente, uma das melhores expressões para traduzir este momento, em relação à formulação de políticas, é “janela de oportunidades”, utilizada originalmente por Kingdon (2006) no desenho de sua abordagem de ciclo de políticas para explicar como a mudança de governo tem o potencial de integrar um conjunto de condicionantes que favorecem transformações na política ou a entrada de novos temas na agenda governamental (SOUZA, 2006; CAPELLA, 2007). 
A formulação do PNFCE, como mencionado, surgiu a partir da eleição do Presidente Lula em 2003, cujo "governo nasceu rodeado pelas expectativas de mudanças em toda a sociedade" (SANTOS, 2012) e pelo alargamento da influência dos movimentos sociais nas políticas públicas em geral, e na educação em particular. Neste sentido, a formulação pareceu ter respondido à demanda social de setores da sociedade civil, grupos, redes políticas e epistêmicas, entre outras, que influenciaram a integração do PNFCE na agenda educacional. O Programa, desde sua origem, envolve os sistemas de ensino públicos estaduais e municipais, por meio da adesão dos entes federados à sistemática de apoio técnico, pedagógico e financeiro. Foi criado pela Secretaria de Educação Básica do Ministério da Educação (SEB), mediante a Portaria Ministerial nº 2.896/2004, tendo dentre os objetivos "apoiar a implantação e o fortalecimento de conselhos escolares [...] na construção coletiva de um projeto educacional no âmbito da escola, em consonância com o processo de democratização da sociedade” (BRASIL, 2004).

A Portaria também define que a implantação do Programa deverá contar com a participação de órgãos e organismos nacionais e internacionais em um trabalho integrado de parcerias para alcançar os objetivos propostos. Neste sentido, de acordo com Aguiar:

a SEB privilegiou, entre os objetivos do Programa, a promoção de parcerias com os sistemas de ensino, por intermédio das secretarias estaduais e municipais de educação, como a principal estratégia política, visando, de um lado, alcançar os demais objetivos e, de outro lado, induzir ações que reforçassem o regime de colaboração entre os entes federativos, tal como previsto na Lei de Diretrizes e Bases da Educação Nacional (2008, p. 133).

A gestão democrática dos sistemas de ensino e consequentemente a maior participação dos sujeitos passaram a figurar como um princípio das políticas educacionais propostas pelo MEC, demostrado também através de outras ações, tais como: Programa Escola de Gestores, a formação de conselheiros municipais de educação (Pró-Conselho) e a formação de dirigentes municipais de educação (Pradime). Nessa perspectiva, o PNFCE foi descrito como "subsídio ao trabalho dos sistemas de ensino em relação à atuação dos conselhos escolares com o objetivo de ampliar as discussões sobre a importância desses órgãos colegiados” (BRASIL, 2006, p. 59).

A SEB em 2007 voltou-se ao atendimento da reestruturação nos processos de transferência voluntária dos recursos da Educação Básica por meio do Plano de Ações Articuladas (PAR). De acordo com o Relatório de Avaliação o desenvolvimento das ações da SEB naquele ano pautava-se em acordos e convênios com inúmeros 
parceiros e órgãos nacionais (União dos Dirigentes Municipais de Educação - UNDIME, Conselho Nacional de Secretários de Educação - CONSED, União Nacional dos Conselhos Municipais de Educação - UNCME) e internacionais (Programa das Nações Unidas para o Desenvolvimento - PNUD, Organização das Nações Unidas para a Educação, a Ciência e a Cultura - UNESCO, Fundo das Nações Unidas para a Infância - UNICEF, Organização dos Estados Ibero-americanos - OEI) que, segundo o mesmo documento, “fortalecem e qualificam sua atuação” (Idem, p. 11).

Através do PAR, o governo federal condicionou, a partir de 2007, as transferências voluntárias e assistência técnica do MEC aos municípios, estados e Distrito Federal à adesão ao Compromisso Todos pela Educação e ao preenchimento dos formulários e instrumentos gerenciais apresentados no PAR. Com isso foram uniformizadas as estruturas e exigências burocráticas e institucionais para a solicitação, repasse e prestação de contas sobre os recursos oriundos do governo federal e destinados às políticas educacionais dos estados e municípios.

Neste mesmo relatório, menciona-se o apoio obtido das experiências das universidades e centros de pesquisa e formação, e principalmente a importância da colaboração entre os entes federados para que o MEC desempenhasse seu papel de articulador e coordenador da política educacional no país.

O PNFCE teve sua estrutura composta inicialmente, por processos de formação continuada dos diferentes agentes da comunidade escolar através de realização de seminários nacional, estaduais e municipais, além de oferta de curso pela modalidade de educação a distância.

Alguns modelos de formações foram oferecidos pelo Programa ao longo de sua existência, priorizando inicialmente técnicos das secretarias de educação dos estados e municípios. No Rio de Janeiro, foi oferecido pela Universidade Federal Rural do Rio de Janeiro (UFRRJ) de 2013 a 2016. Posteriormente, houve ofertas de cursos de formação voltados diretamente aos conselheiros escolares, em parceria com a Universidade Federal do Ceará (UFC) e dinamizadas pelas secretarias municipais de educação, iniciado em 2013 e tendo seu auge em número de cursistas matriculados entre 2014 e primeiro semestre de 2016. No segundo semestre de 2017, aconteceu a única e última oferta do curso para conselheiros escolares.

A extinção do PNFCE deixa uma lacuna acerca desse conjunto de ações com foco na gestão democrática. Neste texto trataremos da construção e execução de uma 
política, que é o curso de formação semipresencial, oferecido pela Universidade Federal Fluminense (UFF), na forma de atividade de extensão universitária.

\section{“Resistir é preciso": a manutenção da perspectiva formativa em âmbito local}

O Curso de Extensão sobre Conselhos Escolares e Gestão Democrática, realizado pela UFF em 2018, em parceria com o Grupo Articulador de Fortalecimento dos Conselhos Escolares do estado do Rio de Janeiro (GAFCE/RJ)2, na modalidade semipresencial, teve como objetivo contribuir com a discussão sobre o fortalecimento dos conselhos escolares e da gestão democrática nas escolas valorizando da participação da comunidade neste processo. Assim, a perspectiva era a manutenção da capilaridade do Programa em âmbito local.

No mesmo período, o MEC ofereceu, por demanda oriunda do PAR, uma formação de 40 horas na modalidade semipresencial para conselheiros escolares em parceria com a UFC e implementadas pelas Secretarias Estadual e Municipais do Rio de Janeiro. Outros modelos de formação continuada foram implementados por iniciativas específicas de municípios que criaram autonomamente suas estratégias para atenderem suas demandas locais, independentemente do PAR. Todavia, os cursos de formação foram descontinuados a partir de 2016, a reboque das mudanças políticas ocorridas à época ${ }^{3}$.

Com o enfraquecimento do PNFCE, a partir de 2016, e sua extinção em 2019, fica uma lacuna de formação continuada para os agentes que representam os vários segmentos que participam direta ou indiretamente da escola, sejam os próprios conselheiros escolares ou os técnicos de secretarias municipais de educação que promovem e estimulam ações de promoção e fortalecimentos dos conselhos escolares, nomeados como Articuladores Municipais. Priorizar os técnicos das secretarias de educação caminha no entendimento da posição estratégica desses agentes, que no âmbito da burocracia, desempenham funções cruciais para a implementação da política.

\footnotetext{
${ }^{2} \mathrm{O}$ GAFCE)foi idealizado pelos consultores do PNFCE devido à necessidade de articulação de técnicos de secretarias da educação que participavam do Encontro Nacional de Fortalecimento dos Conselhos Escolares e que reclamavam que, ao retornarem aos seus municípios, não possuíam mobilização e, consequentemente, não propiciavam ações. O propósito era agregar pessoas que estavam interessadas em articular-se em prol dos conselhos na perspectiva da gestão democrática.

${ }^{3}$ Dilma Rousseff, que foi Presidenta da República Federativa do Brasil pelo Partido dos Trabalhadores (PT), de janeiro de 2011 a agosto de 2016 (reeleita na eleição de 2014), sofreu um processo controverso de impeachment que resultou em sua destituição do cargo.
} 
Nas reuniões ordinárias do GAFCE/RJ, essa demanda tornava-se cada vez mais latente por meio das vozes desses Articuladores Municipais, pois muitos desses agentes não haviam participado de nenhuma das formações anteriormente oferecidas e os que já haviam tido alguma participação entendiam a importância da reflexão e do debate para os desdobramentos de suas ações nas redes públicas de ensino nas quais atuavam.

Nesta perspectiva, o processo de formação continuada sobre conselhos escolares faz-se necessário na medida em que os agentes nele integrados e envolvidos passam a conhecer e se apropriar das funções deste colegiado, com vistas à construção da gestão democrática.

Neste sentido, a coordenação estadual do GAFCE/RJ buscou parceria com a UFF, através da Coordenação do Programa de Pós-Graduação em Educação para a organização e oferta de um Curso de Extensão sobre Conselhos Escolares e Gestão Democrática, inicialmente para os membros deste Grupo, que são técnicos de secretarias municipais de educação.

Este curso foi oferecido na modalidade semipresencial com carga horária de 60 horas, distribuídas entre 24 horas presenciais e 36 horas a distância, com atividades realizadas em Ambiente Virtual de Aprendizagem (AVA). A modalidade presencial foi distribuída em seis encontros de 4 horas.

Os encontros presenciais ocorreram mensalmente, entre maio e outubro de 2018, na UFF. Do ponto de vista epistemológico, nos encontros foram abordados temas que buscavam contribuir para a reflexão sobre a função social da escola pública, relação entre a efetiva participação da comunidade na gestão escolar e a gestão democrática, além da relação entre os conselhos escolares e a melhoria da qualidade da educação e do ensino ofertados nas escolas públicas da educação básica ${ }^{4}$.

As atividades à distância foram realizadas na Plataforma Moodle no AVA desenvolvidas pela equipe técnica do município de Rio das Ostras, que tem formação continuada na modalidade semipresencial, incluindo conselheiros escolares de sua rede de ensino. Esta parceria confirmou a possibilidade de entrelaçamento entre as unidades federativas, como levantado por Abrucio (2010). Neste caso, municípios vizinhos que

\footnotetext{
${ }^{4} \mathrm{O}$ curso foi organizado em torno dos seguintes temas: o sentido da escola e a formação da escola pública no Brasil; o conceito de qualidade da escola e os indicadores de qualidade da educação; a concepção de democracia, de gestão democrática e a relação entre democracia e educação; educação escolar e cultura; a formação e a valorização dos profissionais da educação no Brasil e financiamento da educação.
} 
compartilhavam demanda por formação. A carga horária a distância compreendeu os fóruns de debate e chats, a partir das aulas, das leituras obrigatórias e complementares, disponibilizadas na biblioteca virtual a partir da indicação dos docentes.

No que tange às inscrições foram ofertadas inicialmente 60 vagas. Contudo, após 11 dias de ampla divulgação entre diferentes agentes relacionados ao tema foram realizadas 278 inscrições.

Devido ao grande número de inscritos, a coordenação do curso compreendeu a necessidade de ampliação das vagas a fim de atender a uma demanda reprimida sobre os temas relacionados à gestão democrática com propostas de ações concretas para superação de obstáculos ao funcionamento dos conselhos escolares.

Como apontamos anteriormente, a proposta original do curso era para atendimento aos Articuladores Municipais ${ }^{5}$ integrantes do GAFCE/RJ que eram técnicos de secretarias municipais de educação.

Neste sentido, o critério estabelecido para seleção dos 71 participantes, dentre os 278 inscritos, partiu da premissa de que o curso deveria, além de criar oportunidade de formação prioritariamente para os técnicos das secretarias de educação, contemplar o maior número possível de municípios do estado, considerando a capilarização do curso através da abrangência territorial.

No desdobramento da organização foram estabelecidas parcerias com outras Universidades $^{6}$, através dos docentes convidados, além de membros da equipe técnica do município de Rio das Ostras/RJ para o uso da plataforma e do AVA para as atividades à distância. Além disso, também foi estabelecida como critério para a certificação dos participantes a elaboração de um artigo científico com questões que abordassem temas desenvolvidos no curso, para a composição de um $e$-book a ser lançado em evento posterior.

As inscrições ocorreram através de preenchimento de formulário online, no qual os candidatos informaram: o nome completo, e-mail, telefone para contato, formação, segmento que representa e município de atuação.

Através de uma análise exploratória nas fichas de inscrição observamos que a categoria com maior representação dentre os cursistas selecionados foi a de técnico

\footnotetext{
${ }^{5}$ Para ser Articulador(a) Municipal, o(a) Secretário(a) Municipal de Educação deve indicar o(a) técnico(a) para integrar o GAFCE/RJ.

${ }^{6}$ UERJ e UFRJ.
} 
de secretaria, o que vai ao encontro da proposta inicial desta política de formação. Porém, com a ampliação da oferta, observou-se a confirmação de uma demanda social reprimida, através do interesse pelo Programa, conforme apontavam as inscrições de candidatos que se declararam gestores, professores, pesquisadores, estudante e responsável, que não se constituíam como integrantes dos conselhos ou técnicos.

Contudo, alguns candidatos, ao se inscreverem, identificaram-se em categorias nas quais não estavam efetivamente vinculados, devido à confusa formulação da questão no formulário de inscrição. As disparidades foram percebidas a partir das interações nos fóruns de discussão. Mas não foi possível identificar, nem mesmo através dos fóruns de discussão, a categoria ou segmento de dois participantes.

Após ajustarmos as informações, verificamos a escolaridade dos participantes, conforme apresentado na Tabela.

Tabela. Escolaridade dos participantes do curso por setor social ou segmento do conselho escolar.

\begin{tabular}{|c|c|c|c|c|c|c|c|c|c|c|c|c|}
\hline \multirow{2}{*}{\multicolumn{2}{|c|}{$\begin{array}{l}\text { Participantes do Curso de } \\
\text { Formação }\end{array}$}} & \multirow{2}{*}{$\frac{\text { TOTAL }}{\mathrm{N}}$} & \multicolumn{2}{|c|}{$\begin{array}{l}\text { Ensino } \\
\text { Médio }\end{array}$} & \multicolumn{2}{|c|}{$\begin{array}{c}\text { Ensino } \\
\text { Superior } \\
\text { Incompleto }\end{array}$} & \multicolumn{2}{|c|}{$\begin{array}{l}\text { Ensino } \\
\text { Superior } \\
\text { Completo }\end{array}$} & \multicolumn{2}{|c|}{$\begin{array}{l}\text { Especialização } \\
\text { lato sensu }\end{array}$} & \multicolumn{2}{|c|}{$\begin{array}{l}\text { Especialização } \\
\text { stricto sensu }\end{array}$} \\
\hline & & & $\mathrm{N}$ & $\%$ & $\mathrm{~N}$ & $\%$ & $\mathrm{~N}$ & $\%$ & $\mathrm{~N}$ & $\%$ & $\mathrm{~N}$ & $\%$ \\
\hline \multicolumn{2}{|c|}{$\begin{array}{l}\text { Técnicos da Secretaria de } \\
\text { Educação }\end{array}$} & 32 & 01 & 3,1 & 2 & 6,2 & 14 & 43,8 & 12 & 37,5 & 3 & 9,4 \\
\hline \multirow{4}{*}{ Conselheiros } & Gestor & 10 & - & $\mathrm{O}$ & - & $\mathrm{O}$ & 5 & 50,0 & 4 & 40,0 & 1 & 10,0 \\
\hline & Professor & 8 & 2 & 25,0 & - & $\mathrm{O}$ & 2 & 25,0 & $\mathcal{Q}$ & 25,0 & 2 & 25,0 \\
\hline & Responsável & 1 & 1 & 100,0 & - & $\mathrm{O}$ & - & $\mathrm{O}$ & - & $\mathrm{O}$ & - & $\mathrm{O}$ \\
\hline & $\begin{array}{l}\text { Sem } \\
\text { informação }\end{array}$ & 2 & - & $\mathrm{O}$ & - & $\mathrm{O}$ & 2 & 100,0 & - & $\mathrm{O}$ & - & $\mathrm{O}$ \\
\hline \multirow{5}{*}{$\begin{array}{l}\text { Outras } \\
\text { categorias }\end{array}$} & Professor & 9 & - & $\mathrm{O}$ & - & $\mathrm{O}$ & 4 & 44,4 & 4 & 44,4 & 1 & $\mathrm{O}$ \\
\hline & Pesquisador & 5 & - & $\mathrm{O}$ & - & $\mathrm{O}$ & 2 & 40,0 & $\mathcal{Q}$ & 40,0 & 1 & 20,0 \\
\hline & Gestor & 2 & - & $\mathrm{O}$ & - & $\mathrm{O}$ & 1 & 50,0 & 1 & 50,0 & - & $\mathrm{O}$ \\
\hline & Responsável & 1 & - & $\mathrm{O}$ & - & $\mathrm{O}$ & 1 & 100,0 & - & $\mathrm{O}$ & - & $\mathrm{O}$ \\
\hline & Estudante & 1 & - & $\mathrm{O}$ & - & $\mathrm{O}$ & 1 & 100,0 & - & $\mathrm{O}$ & - & $\mathrm{O}$ \\
\hline \multicolumn{2}{|l|}{ TOTAL } & 71 & 4 & 5,6 & 2 & 2,8 & 31 & 46,6 & 24 & 33,8 & 8 & 11,2 \\
\hline
\end{tabular}

Fonte: Fichas de inscrição e fóruns de discussão.

De acordo com os dados da Tabela, é possível observar o elevado nível de escolaridade dos participantes, destacadamente, entre os técnicos da secretaria de educação e os gestores. Ainda que de modo geral, os dados revelam uma concentração dos participantes nas faixas do ensino superior, entre os responsáveis prevalece o ensino médio. 
A maior parte dos técnicos de secretarias possui curso superior ou pós-graduação, o que possivelmente contribuiu para uma discussão mais aprofundada sobre o trabalho a ser desenvolvido nas secretarias e escolas, a partir dos temas abordados no curso, notadamente o que diz respeito à articulação e ao fortalecimento dos conselhos escolares e da gestão democrática em suas redes de ensino e nas escolas.

De acordo com a Tabela, é possível observar a ausência dos segmentos silenciados nos conselhos das escolas, conforme observado por Werle (2003). Funcionários e alunos não participaram do curso, assim como não foram observadas inscrições desses segmentos dos conselhos.

Outro aspecto relevante é a abrangência territorial do curso, observada a partir das informações dos participantes na ficha de inscrição sobre o município de atuação. Tal informação dimensiona o atendimento em âmbito estadual, como apresentado no Gráfico 1.

Gráfico 1. Relação entre número de municípios do estado e municípios participantes do curso.

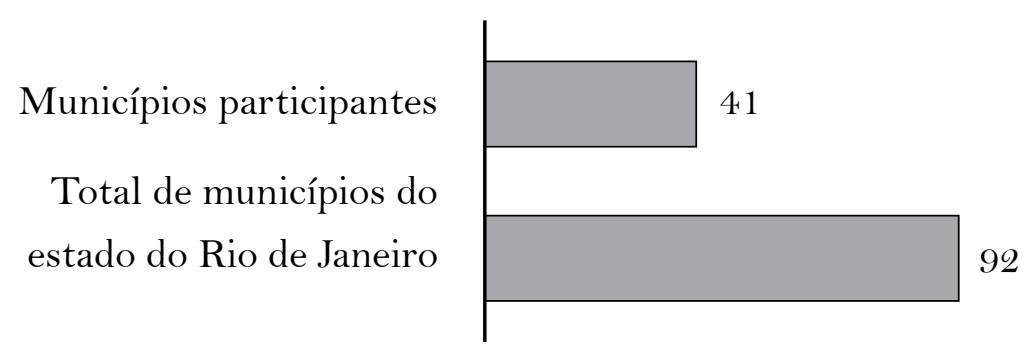

Fonte: Ficha de inscrição dos participantes.

Um dos critérios para seleção dos participantes era a capilaridade desta formação em relação à abrangência territorial, garantindo o atendimento ao maior número possível de municípios, e, desta forma, ampliando a diversidade de vivências e experiências nos conselhos escolares e sobre gestão democrática. Neste sentido, o Gráfico 1 revela a adesão de aproximadamente $45,0 \%$ dos municípios do estado do Rio de Janeiro, através dos participantes.

Outro aspecto relevante é que dos 32 técnicos de secretaria inscritos no curso, 27 faziam parte do GAFCE/RJ como Articuladores Municipais, correspondendo à proposta original do curso. Dos cinco que não compunham o Grupo, três tornaram-se membros até o término da formação. 
O Gráfico 2 ilustra como as Regiões do estado do Rio de Janeiro foram contempladas com representantes no curso de extensão.

Gráfico 2. Municípios atendidos nas Regiões do estado por valores nominais.

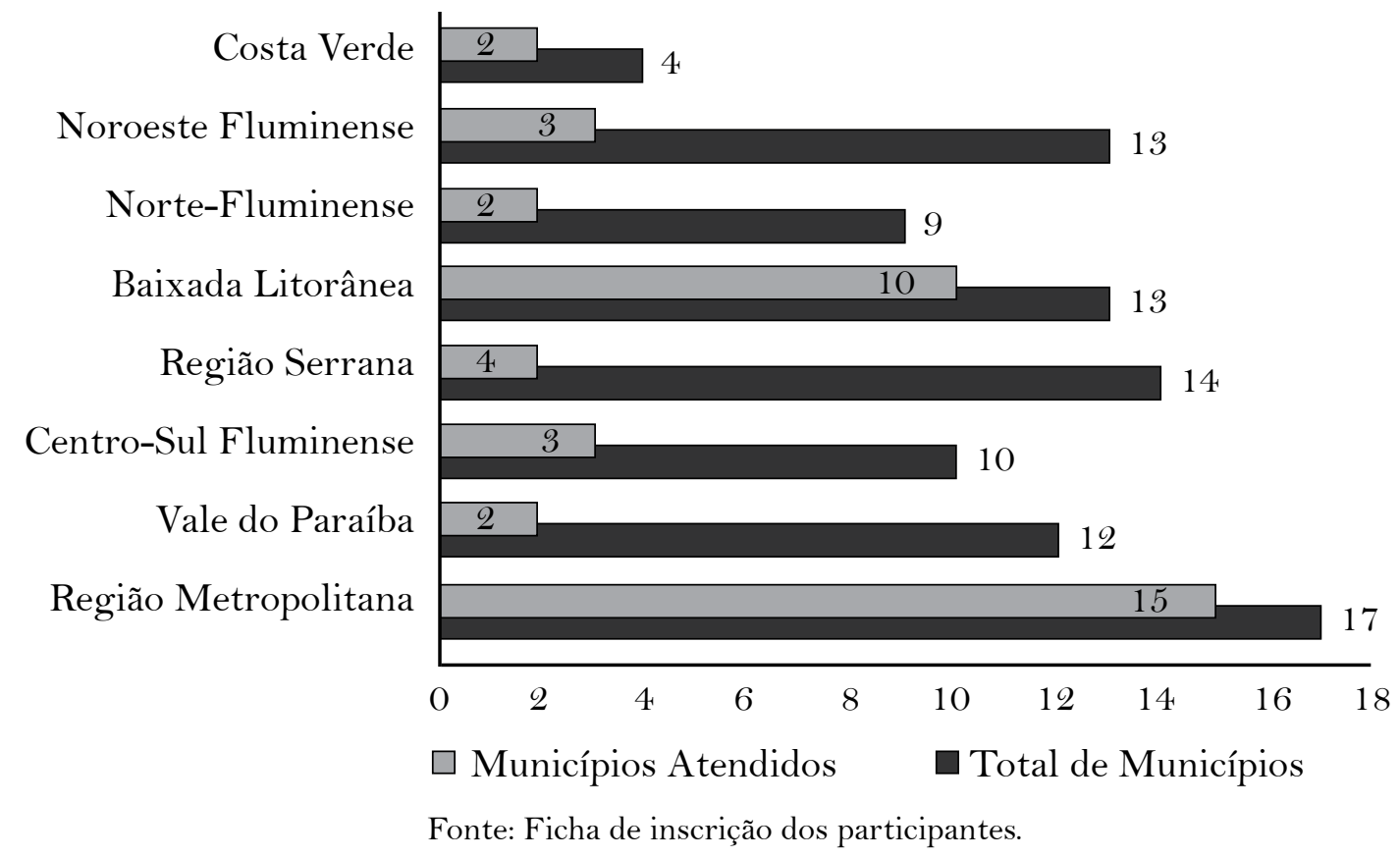

Através do Gráfico 2 podemos observar que as regiões Metropolitana, Baixada Litorânea e Costa Verde tiveram uma representação significativa em termos percentuais - 88,0\%, 77,0\% e 50,0\% -, respectivamente, de municípios contemplados. As regiões com menor representatividade foram Vale do Paraíba, Norte e Noroeste Fluminense, com 16,6\%, 22,0\% e 23,0\% nesta ordem, o que também podemos relacionar com o baixo número de Articuladores Municipais existentes nessas mesorregiões. Apesar do modelo de inscrição que foi adotado ter sido amplamente divulgado pelas mídias sociais e de livre inscrição dos candidatos, os dados sugerem maior atenção a essas regiões, particularmente no que diz respeito a implementação de mecanismos de gestão democrática.

\section{Breves indicações e novas perspectivas: considerações finais}

O modelo adotado para esta política de formação continuada no estado do Rio de Janeiro sobre conselhos escolares e gestão democrática traz alguns apontamentos para reflexão, a fim de analisarmos sobre o que foi ofertado e os ajustes a serem feitos numa possível reedição. 
A modalidade semipresencial pode ser uma boa escolha no que tange à sincronia dos tempos de interação entre os participantes e o uso das ferramentas da educação a distância por meio do AVA. Porém, pode segregar aqueles que não possuem habilidades nesta modalidade para o acesso às informações e conhecimentos produzidos no curso.

Categorias com pouco ou nenhum representante - responsáveis estudantes e funcionários - podem ser justificadas pela escolha deste formato que pode, presumivelmente, ter dificultado a adesão e permanência no curso. Neste sentido, é preciso repensar os conteúdos programáticos previstos a fim de que dialoguem de forma mais próxima com esses segmentos.

O formulário para inscrição também merece nossas considerações, uma vez que o padrão utilizado possibilitou algumas interpretações equivocadas pelos respondentes. Pensar questões que delimitem de forma mais clara e objetiva os que pretendem participar do curso auxiliará ainda na reformulação do Programa, pois é um instrumento de grande potencial de informação que precisa ser melhorado, inclusive para pesquisas acadêmicas e para o debate com os gestores locais.

Refletindo sobre possíveis proposições, o curso de extensão poderia ter como seu resultado final a elaboração de Planos de Ação, visando focar na formação e acompanhamentos dos conselhos escolares. Os(As) técnicos de secretaria elaborariam seus Planos propondo a multiplicação das ações em suas redes públicas de atuação, principalmente porque em sua grande maioria já atuam como Articuladores Municipais em seus municípios. Os conselheiros escolares e demais participantes fariam proposições em seus projetos, fundamentados na realidade. Assim, atendendo às suas demandas, buscariam solucionar os problemas locais, visando a democratização da gestão através dos conselhos escolares.

Consideramos que as análises abrem perspectivas de investigações futuras, que busquem identificar os impactos nos municípios contemplados com os seus representantes, assim como as dos sujeitos locais em prol do fortalecimento dos conselhos escolares e da democratização da gestão em suas escolas.

\section{Referências}

AGUIAR, M. A. S. Gestão da educação básica e o fortalecimento dos conselhos escolares. Educar em Revista, Curitiba, n. 31, p. 129-44, 2008. https//doi.org/10.1590/ S0104-40602008000100009 
ABRUCIO, L. F. A dinâmica federativa da educação brasileira: diagnóstico e propostas de aperfeiçoamento. In: OLIVEIRA, R. P.; SANTANA, W. (Org.). Educação e federalismo no Brasil: combater as desigualdades, garantir a diversidade. Brasília, DF: Unesco, 2010. p. 39-70.

BARROSO, J. A emergência do local e os novos modos de regulação das políticas educativas. Educação: Temas E̊ Problemas, Évora, n. 12-13, p. 13-25, 2013.

BORDIGNON, G.; GRACINDO, R. V. Gestão da educação: o município e a escola. In: FERREIRA, N. S. C.; AGUIAR, M. A. S. (Org.). Gestão da educação: impasses, perspectivas e compromissos. São Paulo, SP: Cortez, 2000. p. 147-76.

BOURDIEU, P. O poder simbólico. Rio de Janeiro, RJ: Bertrand Brasil, 2010.

BRASIL. Ministério da Educação. Relatório de gestão 2005. Brasília, DF, 2006.

BRASIL. Ministério da Educação. Portaria ministerial $\mathrm{N}^{\circ}$ 2.896, de 17 de setembro de 2004. Cria o programa nacional de fortalecimento de conselhos escolares. Diário Oficial da União, 18 set. 2004.

CAPELLA, A. C. N. Perspectivas teóricas sobre o processo de formulação de políticas públicas. In: HOCHMAN, G.; ARRETCHE M.; MARQUES, E. (Org). Políticas públicas no Brasil. Rio de Janeiro, RJ: Fiocruz, 2007. p. 87-122.

GOHN, M. G. Conselhos gestores e participação sociopolítica. São Paulo, SP: Cortez, 2003. HOWLETT, M.; RAMESH, M.; PERL, A. Política pública: seus ciclos e subsistemas: uma abordagem integral. Rio de Janeiro, RJ: Elsevier, 2013.

KINGDON, J. Como chega a hora de uma ideia?. In: FERRAREZI, E.; SARAIVA, E. (Orgs.). Políticas públicas: coletânea. Brasília, DF: Escola Nacional de Administração Pública, 2006. p. 219-24.

LIMA. L. A escola como organização educativa: uma abordagem sociológica. São Paulo, SP: Cortez, 2001.

LOTTA, G. S. Agentes de implementação: uma forma de análise de políticas públicas. Cadernos Gestão Pública e Cidadania, São Paulo, v. 19, n. 65, jul./dez. 2014. https://doi. org/10.12660/cgpc.v19n65.10870

NUNES. A. C. Gestão democrática ou compartilhada? uma (não) tão simples questão de semântica. Cadernos Pedagógicos, Curitiba, n. 2, mar. 1999. 
PARO, V. H. Estrutura da escola e prática educacional democrática. In: Reunião Anual da ANPED, 30. 2007, Caxambu. Anais... Rio de Janeiro, RJ: Associação Nacional de Pós-Graduação e Pesquisa em Educação, 2007.

SABATIER, P. A.; MAZMANIAN, D. A. La implementación de la política pública: um marco de análisis. In: VARELLA, L. A. La implementación de las políticas. Ciudad del Mexico: Miguel Ángel Porrua, 1993, p. 323-72.

SANTOS, K. S. Políticas públicas educacionais no Brasil: tecendo fios. In: Simpósio Brasileiro, Congresso Ibero-Americano de Política e Administração da Educação, 25, 2. 2011, São Paulo. Anais... Brasília, DF: ANPAE, 2012

SOUZA, C. Políticas públicas: uma revisão da literatura. Sociologias, Porto Alegre, n. 16, p. 20-45, jul./dez. 2006. https://doi.org/10.1590/S1517-45222006000200003

SOUZA, C. Estado da Arte da pesquisa em políticas públicas. In: HOCHMAN, G.; ARRETCHE, M.; MARQUES, E. (Org.). Políticas públicas no Brasil. Rio de Janeiro, RJ: Fiocruz, 2007. p. 63-86.

TABORDA, C. R. T. Conselho escolar como unidade executora: limites e possibilidades no processo da construção da gestão democrática. 2009. 197 fls. Dissertação (Mestrado) Instituto de Educação, Universidade Federal de Mato Grosso, Cuiabá, MT, Brasil, 2009. WERLE, F. O. C. Conselhos escolares: implicações na gestão da escola básica. Rio de Janeiro, RJ: DP\&A, 2003.

Submissão em: 30/06/2019

Aceite em: 08/10/2019 